\title{
Influence of High-Speed Bone Drilling on Drill Bit Wear Intensity and Heat Generation
}

\author{
Tomislav Staroveski, Tea Zizak, Miho Klaic, Danko Brezak
}

\begin{abstract}
The objective of bone drilling procedures is to drill a hole at the right angle and position with the minimal negative mechanical and thermal influences on a bone tissue. Whereas machining parameters represents one of the most important influential factors related to the quality of the whole process, the aim of this study was to analyze the influence of standard and high-speed drilling regimes on the drill bit wear intensity and bone heat generation. High-speed drilling parameters were selected according to the required torque amount and limitations in the size and weight of electric servo-actuators suitable for hand-held drilling operations in bone and joint surgery. Experiment was performed on a custom-made testbed using medical drill bits and drilling samples made of artificial biomechanical composite material. Wear intensity of drill bits was expectedly higher when using the high-speed regime. However, average temperature values, compared with the one obtained with standard machining parameters for the same flank wear levels, were up to $15 \%$ lower. Furthermore, drill bit wear process seems to have a very limited influence on the bone heat generation in the case of the high-speed drilling.
\end{abstract}

Index Terms - Bone drilling, Heat generation, High-speed drilling, Tool wear, Thermal osteonecrosis.

\section{INTRODUCTION}

Drilling is the most commonly used procedure in orthopedics and traumatology. The quality of the process depends on surgeon skills, drill bit design and wear condition, cooling efficacy, and machining parameters [1]. The adequate combination of those factors should provide exact drill bit position and angle, low drilling temperatures and cutting forces which will not result in drill bit breakage. Limitation of the drilling temperature is perhaps the most challenging task, because critical temperature values cannot be observed as easily as high cutting forces. According to Karmani [2] and Lundskog [3], if temperature rises to a $50^{\circ} \mathrm{C}$ or higher irreversible damages of bone cells, i.e. thermal osteonecrosis, will occur. Thermal osteonecrosis reduces the quality of the screw fixation of implanted devices to the bone, and it leads to postoperative complications in the case of implant failure due to the loss of bone.

Drilling interventions in bone and joint surgery are completely performed by the operator using hand-held

Tomislav Staroveski, Department of Technology, University of Zagreb/ Faculty of Mechanical Engineering and Naval Architecture, Zagreb, Croatia.

Tea Zizak, Department of Technology, University of Zagreb/ Faculty of Mechanical Engineering and Naval Architecture, Zagreb, Croatia.

Miho Klaic, Department of Technology, University of Zagreb/ Faculty of Mechanical Engineering and Naval Architecture, Zagreb, Croatia.

Danko Brezak, Department of Robotics and Production System Automation, University of Zagreb/ Faculty of Mechanical Engineering and Naval Architecture, Zagreb, Croatia. drilling machines. They are characterized with relatively low levels of rotational speed. For example, one of the leading surgical drills manufacturer DePuy Synthes specifies that all drilling speed attachments are geared to transfer the speed of the drive unit with a maximum speed of up to $1,450 \mathrm{rpm}$ [4-6]. However, drilling at higher rotational speeds and feed rates reduces drilling time, thus influencing on less heat generation and bone temperature elevation. This was the main hypothesis of a number of studies performed in the past 20 years. Although practically all those studies confirmed the usefulness of the high-speed drilling, the reported results are rather ambiguous.

Reingewirtz et al. [7] analyzed the influence of drilling speeds from $400 \mathrm{rpm}$ to $40,000 \mathrm{rpm}$ on bone heating. They observed proportional relationship between the temperature and the rotational speed up to approximately $10,000 \mathrm{rpm}$. The temperature then started to decrease as rotational speed increased up to approximately $24,000 \mathrm{rpm}$. From there on, the temperature became roughly constant up to maximum investigated speed. Authors did not give any information about the feed rate, except that three loads were used $(7.8 \mathrm{~N}$, $12.8 \mathrm{~N}, 19.6 \mathrm{~N}$ ), and that temperature rise only slightly depended on the load. Iyer et al. [8] used three rotational speeds $(2,000 \mathrm{rpm}, 30,000 \mathrm{rpm}$ and 400,000 rpm) and concluded that the high-speed range minimizes heat production. Similar results were reported by Abouzgia and Symington [9]. They experimented with rotational speeds from $20,000 \mathrm{rpm}$ to $100,000 \mathrm{rpm}$ using different constant axial forces $(1.5 \mathrm{~N}-9 \mathrm{~N})$ and observed that the temperature rise and the duration of temperature elevation decrease with the higher rotational speed and force.

However, in their recent research, Abouzgia and James [10] used the same forces interval as in [9] but only one rotational speed of $49,000 \mathrm{rpm}$. They concluded that the temperature increased with force up to about $4.0 \mathrm{~N}$, and then decreased at forces greater than that because of decreased drilling time. Furthermore, performed tests revealed that temperatures were higher in the longitudinal direction than in the circumferential direction, which was attributed to the anisotropic thermal properties of bone. Very similar results were reported in the study performed by Udiljak et al. [11], were authors concluded that the drill cutting speed (rotational speed) should be reduced as much as possible, while the drill feed rate (axial drilling force) should be as high as possible in order to reduce the maximum cortical temperature and its duration above critical level. The same conclusion for axial drilling force or feed rate was reached by Bachus et al [12] and Shakouri et al. [13]. Higher temperatures at higher spindle speeds are also reported by Lee et al. [14], which used 
$800 \mathrm{rpm}$ and 3,800 rpm rotational speed. Feed rate was the same for both speed values $(0.25 \mathrm{~mm} / \mathrm{s})$, and the drilling samples were made from polymethylmethacrylate (PMMA) in order to isolate inhomogeneity and anisotropy effects of the bone specimens.

Partial discrepancies in results from aforementioned studies can be explained by the influence of several factors. Feed rate values were usually not adjusted according to the rotational (cutting) speeds. In some studies information about feed rate was not mentioned at all or was not taken as an influential factor (only one value was chosen). Furthermore, temperature was measured using thermocouples positioned at different distances from the hole edge. In most cases the distance was $>0.5 \mathrm{~mm}$ (in some cases $>1 \mathrm{~mm}$ ), which largely contributed to the temperature measurement inaccuracies, considering the fact that cortical bone tissue is characterized with very low thermal conductivity. It is also anisotropic and highly non-homogenous, which can sometimes substantially influence on experimental results.

Besides that, a relatively high rotational speeds $(>10,000$ $\mathrm{rpm}$ ) were used in a lot of experiments. Such high speeds, which need to be accompanied with the required torque, are not applicable in hand drilling procedures used in bone and joint surgery due to the size and the weight of servo-actuators. At the end, the potential relationship between the drill bit wear dynamics and the high-speed drilling regime was not analyzed.

Considering all those findings and facts two combinations of rotational speeds and feed rates were chosen in this study to analyze drill wear dynamics and temperature variations during drilling. One combination is chosen based on everyday surgical practice and the other was characterized with approximately three times higher rotational speed and feed rate. Selected high-speed regime, together with the adequate drilling torque $(>1 \mathrm{Nm})$, can be provided by electrical servo-motors suitable for hand drilling applications.

\section{MATERIAL AND MEthods}

\section{A. Experimental Setup and Parameters}

The experiment was performed on the 3-axis bench-top mini laboratory milling machine, which has been equipped with $0.4 \mathrm{~kW}(1.27 \mathrm{Nm})$ permanent magnet synchronous motors with integrated incremental encoders (Model APM-SB04A for feed drives and model APM-SA01ACN-8 for main spindle drive, LS Mecapion, Korea), corresponding motor controllers (Models DPCANIE-030A400 and DPCANIE- 060A400, Advanced Motion Control, USA), and ball screw assemblies (Model R16-5B1, Hiwin, Taiwan). It was controlled with the Linux-based, open architecture CNC system (EMC2 v2.3, 2009, from 2011 renamed to LinuxCNC and downloadable from linuxcnc.org) and additionally upgraded with the National Instruments data acquisition hardware and software. Among several types of sensors installed in this testbed, triaxial Kistler piezoelectric dynamometer 9257B coupled with 5017B charge amplifier was used for cutting forces measurements.

Temperature measurements were performed using a custom-made 3D printed temperature probe (Fig. 1).

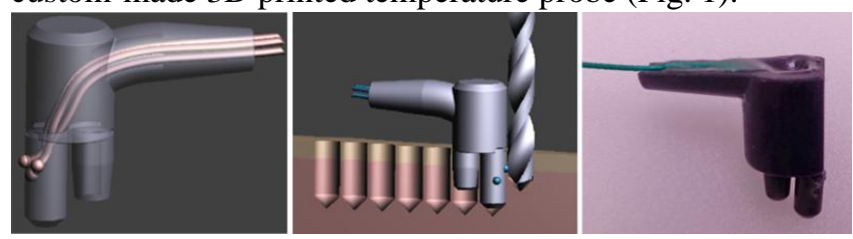

Fig. 1: Temperature probe

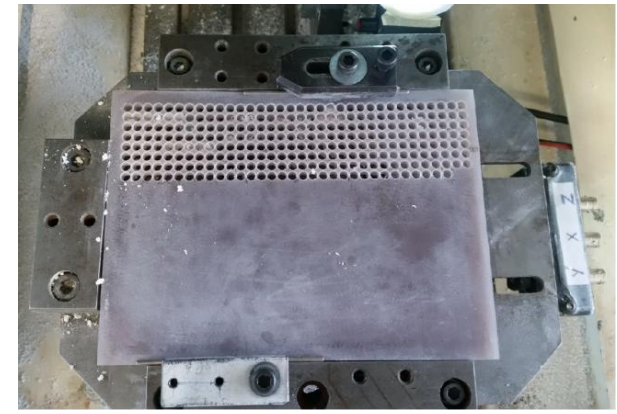

Fig. 2: Drilling sample

The probe can be equipped with three thermocouples positioned at various depths and distances from the cavity wall. In this study, only one K-type thermocouple was installed at the distance of $0.5 \mathrm{~mm}$ from the hole edge and 3 $\mathrm{mm}$ below the drilling specimen surface.

In order to avoid the influence of bone structure heterogeneity on drill wear dynamic, fresh pig bone samples were substituted with the artificial biomechanical test material, the so-called "Short Fiber Filled Epoxy", produced by the Sawbones Co. This fourth-generation cortical bone model, shaped in the form of $130 \times 180 \times 6 \mathrm{~mm}$ block sample, was produced as a mixture of short glass fibers and epoxy resin injected around a solid rigid polyurethane foam core. The drilling sample was fixed using clamping device installed on the top of triaxial dynamometer (Fig. 2).

Three surgical drill bits type 310.450 manufactured by the DePuy Synthes Co. were used in the experiment. Drills had two cutting edges and a diameter of $4.5 \mathrm{~mm}$. They were applied using two machining regimes: standard combination of machining parameters characterized with the 1,300 rpm rotational speed and $1 \mathrm{~mm} / \mathrm{s}$ feed rate, and high-speed regime defined by the rotational speed of 4,700 rpm and $3 \mathrm{~mm} / \mathrm{s}$ feed rate. This high-speed regime was chosen based on its potential of the possible implementation in the next-generation surgical hand-held drilling system.

Precise information about the flank wear intensity of the different drill wear levels has been established with the vision system positioned in the working space of the milling machine. Images of the cutting edges were made using an industrial camera (type DMK41AF02, Imaging Source $\mathrm{GmbH}$, Germany) equipped with telecentric lenses (type TC2309, Opto Engineering S.r.l., Italy).

\section{B. Data Acquisition and Signals Processing}

In the first part of the experiment, one drill bit was used to analyze the influence of both drilling regimes on the temperature and cutting forces variations under the same drill wear conditions. Both cutting edges were first visually inspected by the installed industrial vision system. After that, two initial holes were drilled so that temperature probe could 
be adequately positioned in the composite drilling block sample. Once positioned, the probe ensured thermocouple to be placed $3 \mathrm{~mm}$ under the sample surface. The next (third) hole was then used for temperature measurement while drilling with the standard drilling regime - 1,300 rpm rotational speed and $1 \mathrm{~mm} / \mathrm{s}$ feed rate. Temperature acquisition has been performed using $0.5 \mathrm{~s}$ sampling rate. After drilling the third hole, temperature probe was shifted one hole ahead in a position to measure temperature during drilling of the fourth hole, which was drilled with the high-speed regime $-4,700 \mathrm{rpm}$ rotational speed and $3 \mathrm{~mm} / \mathrm{s}$ feed rate. That way, temperatures related to both drilling regimes were measured using a drill bit worn to practically identical wear level.

The same drill was then used to drill two new holes with standard drilling regime and without temperature measurements in order to increase flank wear. After that, new temperature measurements for both chosen drilling regimes were performed for the next two consecutive holes. Force signals in all three orthogonal directions were acquired simultaneously using $1 \mathrm{~ms}$ sampling rate. During this process, both cutting edges have been periodically (after every fourth hole) inspected by the vision system. Acquired images of cutting edges were processed with the IC Measure software (v.1.2, April 2016) for on-screen measurement and image capture by which maximum flank wear width and flank wear surface parameters were quantified for both cutting edges. Based on maximum flank wear width, four tool wear levels (TWL) were defined (Fig. 3 and Table 1). The comparison of these results indicates very similar flank wear intensity on both cutting lips.

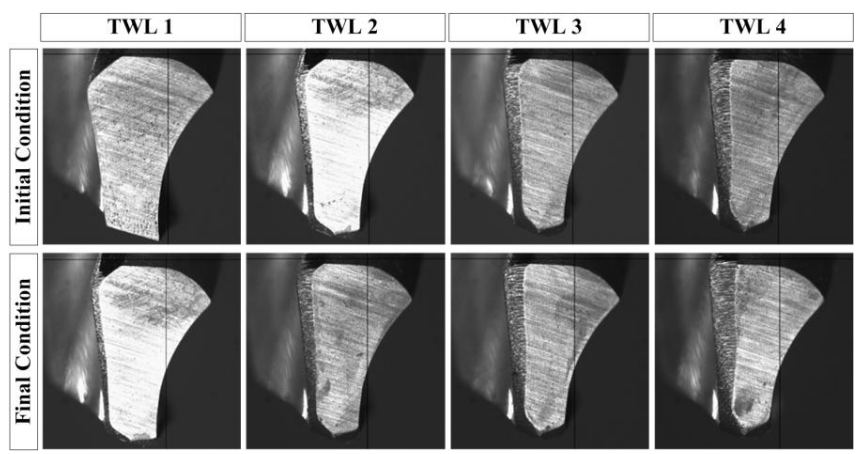

Fig. 3: Cutting edge conditions at the beginning and at the end of the drilling experiment for all four tool wear levels (TWL 1 - TWL 4)

Table 1: Maximum flank wear width ( $\mathrm{mm})$ of the analyzed tool wear levels

\begin{tabular}{|c|c|c|c|c|}
\hline \multirow{2}{*}{$\begin{array}{l}\text { Wear } \\
\text { level }\end{array}$} & \multicolumn{2}{|c|}{ Cutting edge 1} & \multicolumn{2}{|c|}{ Cutting edge 2} \\
\hline & $\begin{array}{c}\text { Initial } \\
\text { condition }\end{array}$ & $\begin{array}{c}\text { Final } \\
\text { condition }\end{array}$ & $\begin{array}{c}\text { Initial } \\
\text { condition }\end{array}$ & $\begin{array}{c}\text { Final } \\
\text { condition }\end{array}$ \\
\hline TWL 1 & 0 & 0.22 & 0 & 0.23 \\
\hline TWL 2 & 0.22 & 0.36 & 0.23 & 0.38 \\
\hline TWL 3 & 0.36 & 0.46 & 0.38 & 0.49 \\
\hline TWL 4 & 0.46 & 0.56 & 0.49 & 0.58 \\
\hline
\end{tabular}

Altogether, 150 holes were drilled until drill bit worn out completely. During the experiment, 76 temperature and forces measurements were acquired - 38 measurements for each of two chosen drilling regimes. Maximum drilling temperature and maximum resultant cutting force of every signal were used as parameters in the comparative analysis of chosen drilling regimes. Resultant cutting force signal was generated based on all three measured orthogonal force components $\left(F_{R}=\sqrt{F_{X}^{2}+F_{Y}^{2}+F_{Z}^{2}}\right)$.The signal was then filtered prior to maximum force value extraction (Fig. 4).

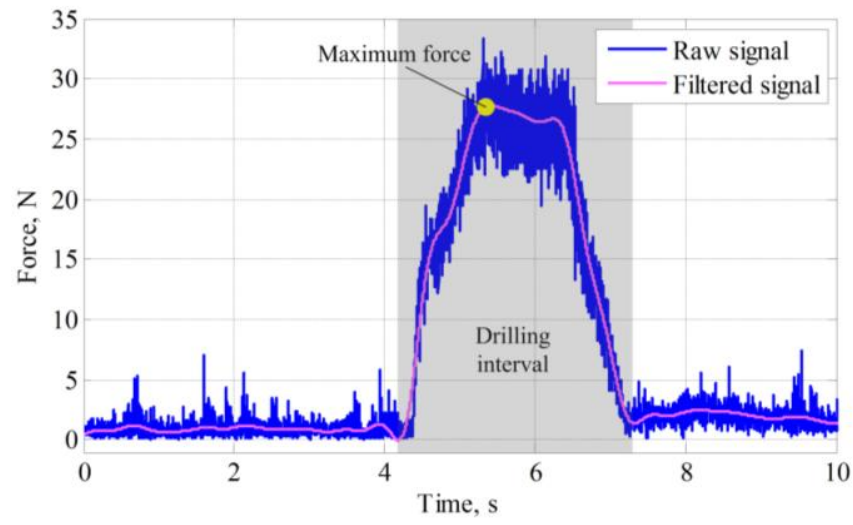

Fig. 4: Raw and filtered signal of the resultant cutting force (high-speed drilling regime)

Filtration was performed using the fifth-order low-pass Butterworth filter whose cut-off frequency was $2 \mathrm{~Hz}$. Filter parameters were established after the analysis of raw (measured) forces signals in the frequency domain using the Fast Fourier Transform (FFT) algorithm.

In the second part of the experiment, the remaining two unworn drill bits were used to analyze tool wear dynamics for each drilling regime separately. First five visual inspections of cutting edges were performed at the beginning of the experiment and then successively after every 5 th drilled hole. The rest of images were acquired after every 10th drilled hole. Both analyzed flank wear parameters (maximum flank wear width and flank wear surface) were extracted from those images.

\section{RESUlTS AND DisCUSSION}

Temperature and force variations for each tool wear level and both machining regimes are presented in Fig. 5 and Fig. 6 , respectively, in the form of Box-Whisker plots. Unlike forces, temperatures have shown higher variations of measured values. This can be explained by small deviations in distances between the temperature probe and the hole edge, which are caused by drill deflections during rotation. Small variations in thermocouple distance from the cutting zone (up to $0.05 \mathrm{~mm}$ ) can have noticeable impact on temperature measurements because of all previously mentioned characteristics of the drilled material.

Although temperature fluctuations seem to be relatively high, it can be noticed that their trend is positively correlated with the drill bit wear in the case of standard drilling regime, i.e., higher average temperature values can be observed at higher wear levels. Furthermore, when comparing average temperatures achieved with both drilling regimes for each wear level separately, higher values were achieved when drilling with the standard regime. The difference between 
average temperatures of both drilling regimes became higher as tool wear progress. Interestingly, average temperatures achieved with the high-speed regime have shown even negative trend for TWL 2 - 4, thus potentially indicating low temperature sensitivity to higher wear levels. This can be explained by three times faster drilling process compared to the standard drilling regime, which has restricted heat generation in the drilling sample.

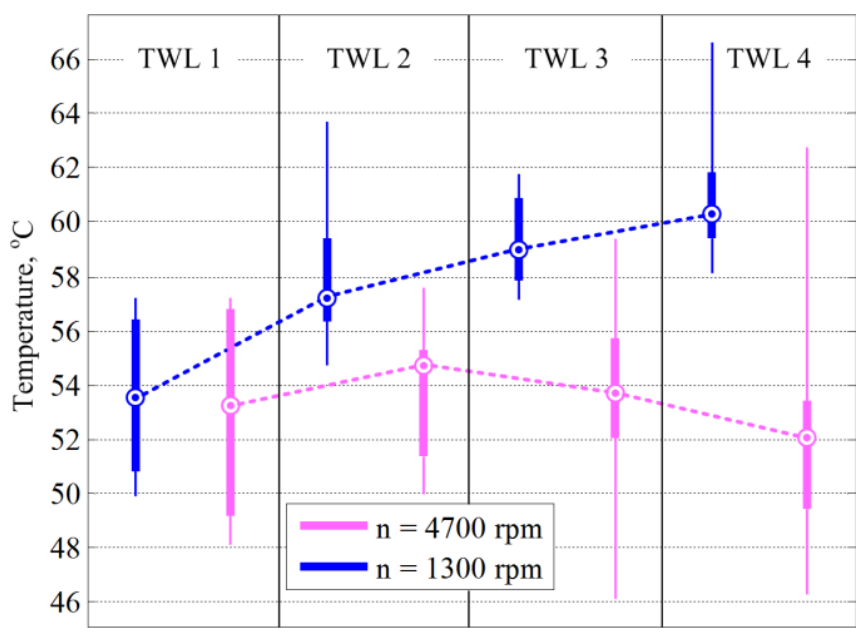

Fig. 5: Maximum drilling temperatures

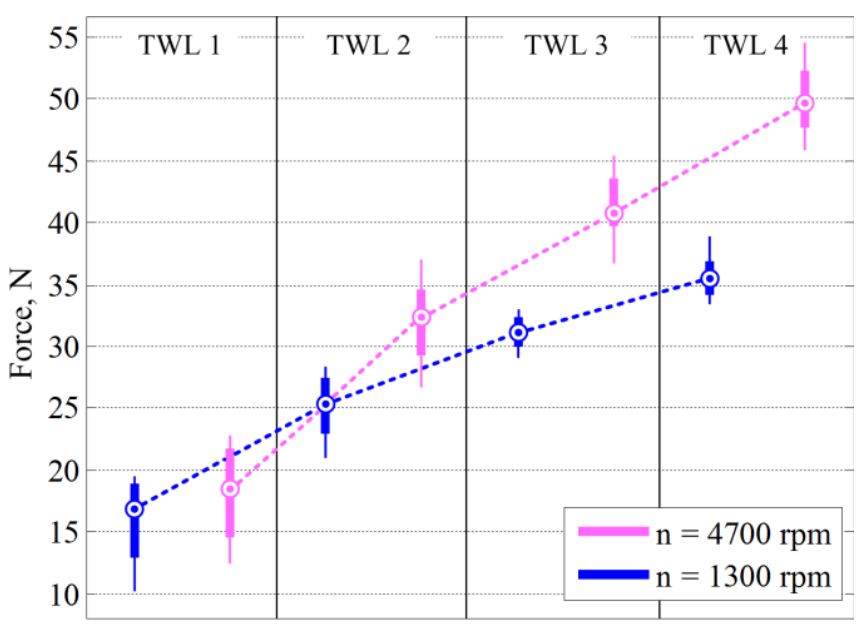

Fig. 6: Maximum resultant drilling forces
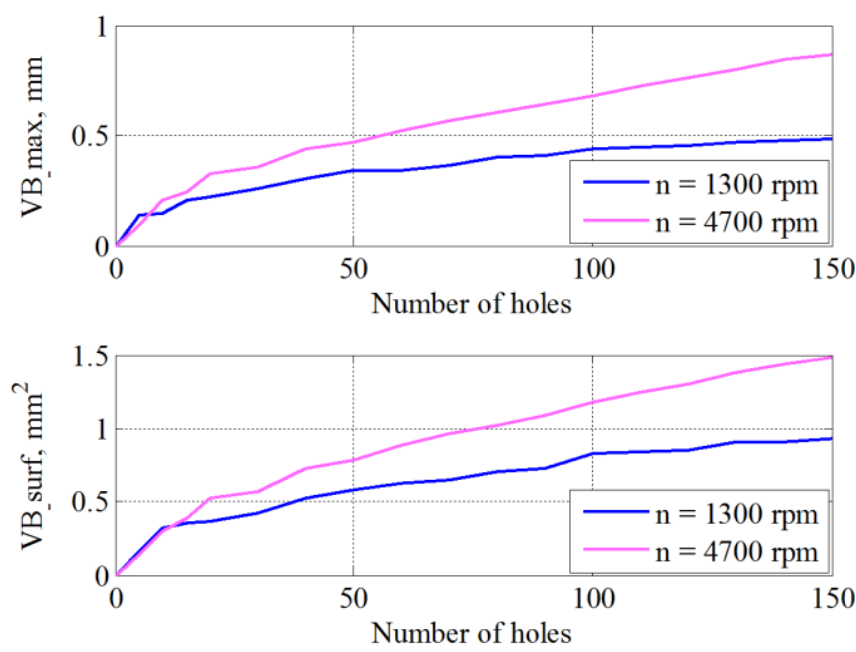

Fig. 7: Diagrams of the maximum flank wear width (VB_max) and flank wear surface (VB_surf) for both drilling regimes
Resultant force have shown positive trend with the tool wear progress for both drilling regimes. Forces achieved with the high-speed regime were usually higher, especially in the case of higher wear levels. This was expected due to the higher feed rate. The highest force values, still acceptable for the hand-held drilling operations, were around $50 \mathrm{~N}$ and were related to the highest and unacceptable wear level (TWL 4) in the clinical practice.

At the end, both drilling regimes were additionally compared using flank wear parameters (maximum flank wear width and flank wear surface) in order to determine their effect on the tool wear dynamics. Those diagrams (Fig. 7) expectedly confirmed higher wear dynamics in the case of the high-speed regime.

\section{CONCLUSION}

Standard and high-speed machining parameters were mutually compared regarding the tool wear intensity and heat generation in bone drilling. Machining parameters of the high-speed regime were chosen based on their potential applicability in hand drilling procedures used in current bone and joint surgery practice. High-speed regime has shown some advantages in the sense of lower drilling temperatures and temperature sensitivity to higher wear levels. The last observation is especially important considering the high influence of tool wear on heat generation and, usually, the absence of hospital standards and activities regarding the condition monitoring of surgical drill bits. The negative characteristic of the high-speed drilling is related to the higher drill bit wear dynamics. Also, in order to fully utilize such machining regime, drilling systems would have to be upgraded with the capability of automated feed movement. In this case, operators would define only drilling location and desired tool direction/angle, while all other activities would be performed autonomously by the machine control system.

\section{REFERENCES}

[1] G. Augustin, et al., "Cortical Bone Drilling and Thermal Osteonecrosis," Clin. Biomech., vol. 27, no. 4, May 2012, pp. 313-325.

[2] S. Karmani, "The thermal properties of bone and the effects of surgical intervention," Curr. Orthop., vol. 20, no. 1, Feb. 2006, pp. 52-58.

[3] J. Lundskog, "Heat and bone tissue - An experimental investigation of the thermal properties of bone and threshold levels from thermal injury," Scand. J. Plast. Reconstr. Surg. Hand. Surg., vol. 9, 1972, pp. $1-80$.

[4] Trauma Recon System User's Manual, DePuy Synthes. Available: www.depuysynthes.com/hcp/power-tools/products/qs/Trauma-ReconSystem-US\#tab3.

[5] Battery Power Line II User's Manual, DePuy Synthes. Available: www.depuysynthes.com/hcp/power-tools/products/qs/battery-power-li ne-ii\#tab3.

[6] Small Battery Drive II User's Manual, DePuy Synthes. Available: www.depuysynthes.com/hcp/power-tools/products/qs/Small-BatteryDrive-II\#tab3.

[7] Y. Reingewirtz, S. Szmukler-Moncler, and B. Senger, "Influence of different parameters on bone heating and drilling time in implantology," Clin. Oral. Implants. Res., vol. 8, no.3, Jun. 1997, pp. 189-97.

[8] S. Iyer, C. Weiss, and A. Mehta, "Effect of drill speed on heat production and the rate and quality of bone formation in dental implant osteotomies. Part I: relationship between drill speed and heat production," Int. J. Prosthodont., vol. 10, no. 5, Sep. - Oct. 1997, pp. 411-414. 
[9] M. B. Abouzgia, and J. M. Symington, "Effect of drill speed on bone temperature," Int. J. Oral. Maxillofac. Surg., vol. 25, no. 5, Oct. 1996, pp. 394-399.

[10] M. B. Abouzgia, and D. F. James, "Temperature rise during drilling through bone," Int. J. Oral. Maxillofac. Implants., vol. 12, no. 3, May Jun. 1997, pp. 342-353.

[11] T. Udiljak, D. Ciglar, and S. Skoric, "Investigation into bone drilling and thermal bone necrosis," Adv. Prod. Eng. Manage., vol. 2, no. 3 , 2007, pp. 103-112.

[12] K. N. Bachus, M. T. Rondina, and D. T. Hutchinson, "The Effects of Drilling Force on Cortical Temperature and Their Duration: an in Vitro study," Med. Eng. Phys., vol. 22, no. 10, Dec. 2000, pp. 685-691.

[13] E. Shakouri, et al. "Experimental and analytical investigation of the thermal necrosis in high-speed drilling of bonery," Proc. Inst. Mech. Eng. $H$, vol. 228, no. 4, Apr. 2014, pp. 330-341.

[14] J. Lee, O. B. Ozdoganlar and Y. Rabin, "An experimental investigation on thermal exposure during bone drilling," Med. Eng. Phys., vol. 34 no.10, Dec. 2012, pp. 1510-1520. 